\title{
3 Research Square \\ Rural and Urban Differences in Overdose Response and Prevention Among Persons Who Inject Drugs
}

Suzan M Walters ( $\nabla$ suzanmwalters@gmail.com )

Stony Brook University https://orcid.org/0000-0002-2975-2893

Marisa Felsher

Johns Hopkins University

David Frank

New York University

Tarlise Townsend

New York University

Brandon Muncan

Stony Brook University Medical Center: Stony Brook University Hospital

Samuel R Friedman

New York University

Danielle Ompad

New York University

\section{Research}

Keywords: Overdose, persons who inject drugs (PWID), fentanyl

Posted Date: March 11th, 2021

DOI: https://doi.org/10.21203/rs.3.rs-262761/v1

License: (9) This work is licensed under a Creative Commons Attribution 4.0 International License.

Read Full License 


\section{Abstract}

\section{Background}

Overdose is a leading cause of morbidity and mortality among people who inject drugs (PWID). Illicitly manufactured fentanyl is now a major driver of opioid overdose deaths. This analysis explores ruralurban differences in overdose experiences among PWID. We focus on perceptions of fentanyl and overdose prevention and reversal strategies.

\section{Methods}

Semi-structured interviews were conducted with 59 participants who injected drugs, 19 from rural southern Illinois and 40 from New York City (NYC). Seven key informants were also interviewed (three from Illinois and four from NYC) to provide additional perspectives. Data were analyzed using constant comparison and theoretical sampling methods.

\section{Results}

Participants in urban NYC described most commonly injecting heroin and fentanyl, which differed from the rural Illinois drug market that was dominated by methamphetamines. Despite these geographic differences, participants from both locations were concerned about the growing presence of fentanyl in their drug supply and many disclosed overdose experiences. Strategies to lower overdose risk included purchasing drugs from trusted network members and partial drug injection, however, fentanyl test strip use was low in both locations. A key difference emerged related to the use of naloxone; NYC participants commonly described using naloxone as a primary overdose response, but participants in rural Illinois did not. Low naloxone use in Illinois was attributed to perceived risks of its use, such as fear of arrest and opioid withdrawal symptoms the naloxone receiver may experience.

\section{Conclusions}

Despite similarities in fentanyl awareness and concern, important rural-urban differences emerged related to access to overdose prevention and reversal resources. Findings can inform regional-specific interventions to reduce overdose risk among PWID.

\section{Introduction}

Overdose is a leading cause of morbidity and mortality among people who inject drugs (PWID) (1). A recent report published by the Centers for Disease Control and Prevention (CDC)

reported that approximately 81,230 drug overdose deaths occurred in the United States between June 2019 and May 2020, which is the largest number of drug overdoses for a 12-month period ever recorded (2). The increases in drug overdose deaths appear to have accelerated during the COVID-19 pandemic (3, 4). 
Illicitly manufactured fentanyl is now the primary driver of opioid overdose deaths. Fentanyl is a synthetic opioid 50 times more potent by weight than heroin with a rapid onset of action and relatively short duration of effect (5). A recent report published by the CDC detected fentanyl in $56 \%$ of opioid overdose deaths (6). Manufactured in clandestine labs outside of the US, fentanyl typically enters the country alongside heroin and other drugs through illicit channels before being sold by itself or used to adulterate other drugs (7). Persons who inject drugs (PWID) may become exposed to fentanyl either intentionally, by seeking to use fentanyl, or unintentionally when their illicit drugs have fentanyl in them without their knowing (8). This is concerning because only a small amount of fentanyl is needed to result in an overdose (5).

There are a variety of strategies that PWID may implement to prevent overdose or respond to an overdose in real time. As many PWID may be unaware of the presence of fentanyl in the substances they consume, recent innovations in rapid drug testing have allowed for the use of test strips to detect fentanyl (9). These test strips enable PWID to check their drug supply for the presence of fentanyl before consumption by dissolving a small amount of the substance or a sample of drug residue in water (10). Another overdose prevention technique is the use of naloxone, an opioid antagonist, to reverse the effects of opioids. Naloxone has been used by the medical community since the early 1970 s and was first distributed to high-risk individuals in the late 1990s. From 1996 to June 2014, 136 opioid overdose education and naloxone distribution (OEND) programs in the US provided naloxone kits to 152,283 people and reported 26,463 potential opioid overdose reversals (11). PWID report other overdose prevention techniques that range in effectiveness, such as shocking people with water, injecting the person overdosing with a salt solution $(12,13)$, and partial drug injection. Partial drug injection comprises a number of practices, such as "slow shots" where the user injects a portion of the solution in the syringe, keeping the needle in the injection site, and continuing or withdrawing the syringe and "tester shots" where the solution is divided into separate injections (14). PWID may also rely on trusting relationships that they foster with drug sellers to confirm that their drugs are not adulterated with fentanyl (15-18).

The effectiveness of, and access to, particular overdose prevention interventions may vary depending upon rural and urban locations, which could include differences in the type of opioid (i.e., prescription opioids, heroin, illicit fentanyl) responsible for overdoses. This is important because a single dose of naloxone may be less likely to reverse an overdose when fentanyl is used $(19,20)$. While all states have demonstrated an increase in opioid morbidity and mortality during the past decade, death and injury from opioid use are concentrated in states with large rural populations, such as Kentucky, West Virginia, Alaska, and Oklahoma (21-23). Historically, prescription opioids have made up a larger share of rural drug-related deaths than either heroin or illicit fentanyl and in contrast, illicit fentanyl contributed the largest share of drug overdoses in urban locations (24). However, emerging research is showing increased fentanyl saturation in drug markets in rural locations $(25,26)$. Overdose risk in rural locations is further exacerbated by health care shortages, underfunding of social services, and longer distances to emergency services $(27,28)$. As a result, there is a scarcity of opioid use disorder treatment services and providers (29-33), syringe services programs (34) and health department resources for opioid use and mental health (35). This further limits rural PWID's awareness of, and access to, overdose prevention 
resources, particularly biomedical tools such as fentanyl test strips and naloxone. Taken together, the relatively recent emergence of fentanyl in these rural locations, along with barriers to healthcare access, may leave rural PWID and providers serving them (e.g., drug treatment providers, SSPs, etc.) less prepared to prevent fentanyl overdose $(22,23)$, compared to those in urban locations.

Little is known about how PWID's awareness of fentanyl in the local drug markets differs in rural and urban locations. Furthermore, few studies have explored rural and urban differences in the techniques PWID implement to prevent and respond to overdose. This study sought to understand rural-urban differences in the context of drug use, perceptions of fentanyl in the drug supply, overdose prevention strategies, and non-fatal overdose experiences. Such knowledge is key to our ability to understand the current and potential future trajectory of the overdose crisis and to devise efforts to mitigate it.

\section{Methods}

Sample

PWID were recruited from syringe service providers (SSPs) in rural southern Illinois and New York City. To be eligible to participate, participants had to be 18 years or older and have injected drugs within the last year. In Illinois, we partnered with an existing research project, Ending Transmission of HIV, HCV, and Overdose in Rural Communities of People Who Inject Drugs (ETHIC) who worked closely with a local SSP. The Illinois SSP had two physical locations but functioned mostly as mobile outreach that delivered products to participants' homes. Services offered included distribution of sterile injection equipment and contraceptives, HIV and STI testing, and opioid overdose prevention services. The SSP covered 16 southern counties of Illinois, encompassing several hundred miles of rural territory. Potential PWID participants were identified by study staff on the ETHIC project and contacted via telephone or in person by our partner SSP to schedule an interview for this study. Current injection drug use was confirmed by consulting with staff at the SSP, as well as reviewing potential participants' ETHIC survey data.

In NYC, we partnered with an SSP located in Manhattan. The NYC SSP offered a comprehensive set of services, including provision of new injection equipment, pipes for smoking drugs such as crack cocaine and/or methamphetamines, and contraceptives; HIV and HCV testing; on-site HCV treatment; opioid overdose prevention services; medical and mental healthcare counseling and referrals; case management services; various peer groups; computer and internet access; phones; and food. NYC interviewers (names redacted for blind review) would spend one day a week at the SSP to build rapport with participants and staff, and to gain overall knowledge about the SSP and its clients. NYC interviewers also consulted the SSP staff to identify eligible PWID.

We also conducted key informant (KI) interviews to provide valuable complementary insight into PWID's lived experiences (36). The original eligibility criteria for KIs was being 18 years or older and spending over 30 hours per week working directly with PWID. During interviews, participants in Illinois described important interactions with pharmacists and emergency medical services (EMS) employees, so we purposively sampled members of these professions to be Kl's to contextualize PWID's experiences in the 
rural setting. These additions were made toward the end of data collection and our sampling was adjusted due to the constant comparative methods we used (37). Some Kl's may have had a history of drug use, however, many of them did not disclose drug use to us during the interview and we did not ask about their drug use.

\section{Data Collection}

Fifty-nine semi-structured interviews, 19 from Illinois and 40 from NYC, were conducted with PWID participants from August 2019 through February 2020. We also conducted interviews with seven Kl's: four in NYC and 3 in rural Illinois. Data collection ended due to the COVID-19 pandemic. Therefore, data for this analysis do not contain information about COVID-19. Interviews were conducted by researchers (three in Illinois and two in NYC). Researchers in both sites were trained by the PI of the project in ethnographic methods of observation, semi-structured qualitative interviews, writing field notes and memos, and coding. Interviews were audio recorded and ranged in length from thirty minutes to two hours. Written informed consent was obtained from all participants at the beginning of the study visit, and each participant received $\$ 40$ for their time.

Interviews in Illinois were conducted in the SSP's mobile van or in locations agreed upon by the interviewer and participant. NYC interviews were conducted in a private room at the SSP. Study staff in both Illinois and NYC had strong community ties from spending time within the SSP, however they were not SSP employees, which fostered trust and rapport which we believe increased the credibility of findings (38). After each interview, study staff immediately created a memo describing their observations and experiences. Memos included details of the interview by the domains explored, body language and tone of the interviewee, observations of the interview site, perceived challenges with interview questions, and any other relevant information that would not come through from a transcript $(39,40)$.

\section{Interview Structure}

The interview guide was semi-structured with open-ended questions allowing for participants to discuss what resonated most with them for each particular domain and for the interviewer to probe on questions depending on participant responses. The domains relevant to this analysis were the geographic context of drug markets, perceptions towards fentanyl in the drug markets, and overdose prevention and response techniques used by participants. PWID participants were first asked to contextualize their drug use by answering questions such as, "Tell me about the types of drugs you use" and "How do you get drugs?" To identify how participants perceived fentanyl in their drug supply, participants were asked, "Tell me about your experiences with fentanyl." Next, interview guides explored the overdose prevention and response strategies employed by participants. To explore overdose prevention strategies, participants were asked to describe their experience with using fentanyl test strips, including the frequency of their use. To explore experiences with responding to overdoses, we asked, "Have you ever seen a person overdose?" If they answered yes, participants were asked to describe the story of what happened when they witnessed an overdose, including how they responded to the overdose. Participants were asked if they use naloxone during this event. When participants witnessed more than one overdose, interviewers 
encouraged them to tell a detailed story about whichever experience was most salient to them, which was often the most recent overdose experience. We then asked questions about participants' general experiences with naloxone by asking questions about access to naloxone, comfort carrying naloxone, and experiences being trained to administer naloxone and first-hand experience administering naloxone. Demographic characteristics including age, gender, sexual orientation, education, and employment were collected at the end of each interview.

$\mathrm{KI}$ interview guides covered the same domains but asked specific questions relevant to the positions the key informants held. Kls were first asked to contextualize the geographic context of drug use by answering questions such as, "Tell me about the [city/town]," "Tell me about [organization/company] you work at," and "Tell me about how you work with people who inject drugs." Kls were then asked to "Describe the types of drugs used in [city/town]" and "tell me about any overdoses in [city/town]." They were also directly asked about fentanyl ("Please tell me what you know, if anything, about fentanyl") and fentanyl test strips ("Can you tell me what you know, if anything, fentanyl test strips?").

\section{Data Analysis}

Audio recordings from the interviews were reviewed and professionally transcribed. Informed by grounded theory, constant comparison, and theoretical sampling methods (37), we immediately transcribed the interviews after conducting them and reviewed the transcript to note any immediate themes that arose, which might need to be addressed by changing our interview guide or recruitment methods. At that point the transcript was uploaded to Dedoose (Version 8.3.17) for qualitative coding and assigned to one of three coders. We coded line by line and then grouped codes into themes. Relevant themes were compiled in a qualitative codebook, and the codebook continued to change throughout the coding process as new themes emerged (41). Codes were reviewed through dialogue about the data and codebook weekly, and a final consensus was reached among the three coders. Once coding was finished, we identified themes related to overdose risk, prevention and response. We then sub-set the data to compare and contrast how participants' experiences differed in urban NYC and rural Illinois. Pseudonyms were given to participants to protect their identities when presenting quotes in this manuscript (42).

\section{Results}

We interviewed a total of 59 PWID, 19 from rural Illinois and 40 from New York City. Of the 19 from Illinois, 12 preferred stimulants and 7 preferred opioids. Of the 40 from NYC, 16 preferred stimulants and 24 preferred opioids. We also interviewed seven $\mathrm{KI}$, four from rural Illinois and three from NYC. KI occupations were as follows: four were SSP staff (one executive director, one office manager, one nurse, and one coordinator of outreach services), two were paramedics and one was a pharmacist.

Demographic characteristics of PWID and key informants are found in Table 1 and Table 2, respectively. Three overall themes emerged from the data: (1) the geographic context of drug use (2) overdose prevention practices; and 3) overdose reversal practices. Within the second theme of overdose prevention practices, three important subthemes emerged related to social networks as risk mitigation, familiarity 
with fentanyl test strips, and modification of drug practices when they suspect their drugs contain fentanyl. We found that there were similarities and differences between the rural and urban environments as they related to drug use and overdose, which we highlight below.

\section{The Context of Drug Use in NYC and Rural Illinois}

There were important rural-urban differences in the drug markets between NYC and rural Illinois. In NYC, participants noted that heroin and fentanyl were the most commonly injected drugs: For example, Patrick, a predominately methamphetamine user in NYC described, "Heroin and fentanyl are pretty much our injection drugs." However, in rural Illinois, the market was dominated by methamphetamines. Brandon, a staff member of the Illinois SSP and KI stated, "We recognize... that in Southern Illinois we have a lot of meth users, and those using methamphetamine... they are injecting, most of them are."

Despite these differences, most participants in both locations were aware that drugs in the local drug market were adulterated with fentanyl, and that injection of fentanyl could be fatal. Participants in both locations often used words like "dangerous" and "afraid" when discussing this possibility. In NYC, this was mostly discussed in the context of heroin, crack cocaine, and cocaine: "Right now fentanyl is the number one killer between the chemicals that's in the heroin and the fentanyl. It's giving people overdose...some people don't know how much of that shit is in the dope" (Bret, NYC, preferred heroin). In Illinois, conversations also included fentanyl being in methamphetamine:

[Fentanyl is] strong... It's real dangerous, and...it's been an epidemic here lately. I tell everybody I know that they need to watch out if they're trying to purchase something because there's a lot of fentanyl in the meth nowadays, and it's so strong... it'll kill you if you don't know what you're doing." (William, Illinois, preferred heroin)

Despite awareness that fentanyl is in the overall drug market, participants described being unsure if fentanyl was in the specific drugs they used, which caused fear. For example, Eliza in NYC said, "I fear, I have a fear, I'm not going to lie to you. I have a fear...So many people dying...Becauseyou don't know what you're shooting, you don't know what you're putting up your nose anymore" (Eliza, NYC, preferred heroin)." Similarly, in Illinois Steven said, "Fentanyl kills people. I know people that mix it with heroin and don't tell people, and that's what ends up being what they call a 'hot shot'... It'll ruin their life. It's fatal" (Steven, Illinois, preferred methamphetamines).

Participants' narratives suggest that fentanyl is becoming a common drug in both locales. They also described a disconnect between awareness of fentanyl in the overall drug market, but uncertainty over whether it is in the actual drugs that they purchase in both rural and urban locations. Uncertainty of the purity of their drugs caused distress, though actions taken to prevent and respond to overdose differed by setting, which we detail in the following sections.

\section{Overdose Prevention Strategies}


In both locations, participants described how purchasing drugs from trusted drug sellers was one of the initial strategies they employed to mitigate overdose risk. Many participants described that they had a positive relationship with the person who sells them drugs, and they believed the drug sellers cared about the safety of their clients. This close relationship made them feel like drug sellers were valuable members embedded within their community. Timothy made the point, "The drug dealers care about their users" (NYC, preferred heroin). One way that drug sellers were perceived to care about the health of clients was through the secondary distribution of sterile syringes along with the drugs. For example, Greg, a client of the local Illinois SSP, explains how he informally supplies new injecting equipment to dealers who then distribute injecting equipment to their clients when they purchase drugs::

I got six or seven major dealers in town. They will come to me when I get my shipment, you know, my package of, you know, syringes and stuff, and they will fight to get them. So, they can pass them out with their shit. So, we've kind of formed a little community. (Greg, Illinois, preferred methamphetamine)

Kelly, a SSP employee in NYC and KI, also described how drug sellers helped to prevent physical violence within the streets:

So we have a funny relationship with the dealers...In a way they are a bit protective of us. Like we had someone who was violent... which doesn't happen a lot...but if we had someone that we needed a little bit help regulating, not that they would rough anyone up but they have a lot of control on what happens on this block. They kind of keep the peace and they're very respectful.

Participants perceived that their risk of accidental overdose was significantly lower if they purchased drugs from these trusted sellers. Tom reported exclusively purchasing drugs from a single seller or from only a small number of sellers, from whom he had purchased before or from whom friends/acquaintances had purchased: "I've got a decent plug so most of the time, it's not an issue. It's good stuff" (Illinois, preferred heroin)." Similarly, in NYC: "I don't just put anything in my body. If I do not know you, I am not going to purchase anything" (Dana, NYC, preferred methamphetamine).

However, despite buying from the same person or trusted drug sellers, some participants remained uncertain about the presence of fentanyl in their drugs. Luke discussed his suspicion of fentanyl being in his drugs without him knowing even though he purchased the drugs from a regular seller he has known for years: "I noticed I felt [it] pretty quick. I felt and I'm starting to say to myself, 'yeah that was good.' I didn't say anything, but I thought it was something else. It might have been, had some [fentanyl] a little bit in it" (NYC, preferred heroin). Another problem that participants discussed was when sellers they trusted were not consistently available. For example, Carlos, when asked if he buys from the same person responded, "I try, but sometimes his product goes down or he's not around" (NYC, preferred heroin). The illicit nature of selling drugs affected participants in that their sellers might not be available due to incarceration. A few NYC participants mentioned recent events where multiple drug sellers in the area were arrested, which made it more challenging to acquire drugs. Tanya said, "It's getting harder and harder to find heroin around here, but for whatever reason a lot of people, just this past week about six of my dealers got arrested" (NYC, preferred heroin). 
In addition to using trusted social ties to purchase drugs, KI Maria in NYC described how SSPs may also serve as an important social connection in PWID's lives that shared overdose prevention information. Namely, there was a "bad batch" program at the study SSP, in which clients who have accidentally overdosed and/or have witnessed or heard of overdoses after injecting drugs purchased from a certain drug seller can report the "bad batch," and the SSP would post the information on a bulletin board for all clients to see. Maria reports that this system could potentially help PWID to avoid samples that could lead to overdose. Of note, Maria also said that in some cases, PWID may seek out drug sellers and samples from the "bad batch" list for the potency of the drug. Therefore, she acknowledged that other overdose prevention practices (like partial injection, described below) should be used in conjunction with information dissemination:

When a participant overdoses... we ask them what they took, and some will say, 'Superman bag, blue bag.' We have a board, a "bad batch board" we call it, and we put down all the bags that people overdosed on. We try to get as much information as possible so we can start spreading the word to other people about what someone overdosed on, which is a pro and a con. Some people are chasing overdoses...some would want to seek it out. They get really interested and they want to try it and see if it's strong. They're not thinking about overdoses. We actually encourage everyone to practice other kinds of harm reduction.

Taken together, participants in both locations relied on trusted dealers to alert them to the presence of fentanyl in their drug supply as a primary overdose prevention method. However, participants' reports demonstrated that this information may not always be accurate, or that they may have difficulty accessing trusted drug dealers, highlighting the need for other, more accurate and accessible, overdose prevention methods.

\section{Fentanyl Test Strips}

Despite concerns about fentanyl, and the insecurity of using trusted drug dealers, few participants in either location knew about or used test strips to detect fentanyl in drug samples. In the case that a participant was unaware of fentanyl test strips, the interviewer provided information about their use and referred participants to the partner SSP for test strips and in some cases worked with the SSP to get the participant test strips and taught them how to use them. In response, the majority of participants acknowledged the importance of being able to test their drug samples and expressed interested in using test strips in the future. "I've never tried [the strips]... Where can I get those?... I'm going to get a couple... Especially the way they're mixing stuff so much. People dying like flies." (Shane, NYC, preferred heroin). Similarly, in Illinois, Jessica recognized that fentanyl was being added to many drugs. While she had heard of test strips, she neither used them in the past nor knew how to access them. Nevertheless, she was interested in starting to use test strips in the future if offered by the study SSP. Jessica said:

I don't know much about them, but I do not know that [SSP] has them. That way you can test the drug that you are doing because now everything's being laced with [fentanyl]. I've never used them. [I plan to use them] if I can get them through [SSP]. I would definitely use them every time... I never thought that [they 
offer strips at the SSP]. I never knew that they did that kind of program. (Illinois, preferred methamphetamine)

Among the small percentage of participants who used fentanyl tests strips in NYC or Illinois prior to the interview, most had positive experiences with the strips though used them infrequently:

[I only use test strips] when I have a question about [the drug]. You know, I've got a decent plug...most of the time...it's not really an issue. It's good quality. But if there's ever a question...I'll test it. I don't have any more of [the strips] now though...I actually need to get some more of them. (Tom, Illinois, preferred heroin)

Similarly, Dana described infrequent use of strips, and only with her opioids: I'm thinking about trying it for my crack...recently in this neighborhood I've been getting stuff and I've been like, 'What the fuck?' So I'm going to test it and find out just to see...I don't use [the test strips] that often. I used them a few times within the last few months (NYC, preferred methamphetamine).

In contrast, one participant expressed resistance to the use of fentanyl test strips. Marc, who used test strips in the past, explained that he stopped testing his drug samples because he expected fentanyl to be present in all samples. His expression of frustration with the prevalence of fentanyl in drugs revealed developing fatalism with regard to overdose:

Fentanyl is all there is right now. If you find heroin, you're lucky... I've used the test strips a few times but I stopped doing it because everything's coming positive. What the heck am I going to keep testing it for? I know what it's going to be, it's fentanyl every time... the way I see it, when you're going to die, you're going to die no matter what. Even if you take Fentanyl or cross the street. (NYC, preferred methamphetamine)

One Illinois KI who was a paramedic, David, also explained that fear of being judged negatively or prosecuted is major deterrent to obtaining test strips in small-town rural locations:

Despite fentanyl test strips being available in the SSPs used by participants in both locations, participants' narratives revealed limited awareness and use of fentanyl test strips. While resistance may be attributed to futility stemming from the perception that fentanyl is guaranteed to be in all drugs, which was reported in urban NYC, our KI in rural Illinois suggested that PWID in small towns may also resist using them due to concerns of being stigmatized if the strips had to be collected in public spaces.

\section{Modification of Injection Drug Practices}

Participants previously described the strategies they implemented to determine if their drugs confer added risk for overdose. Just as important was understanding how participants modified their drug use behaviors (or not) in response to this information. Participants in both NYC and Illinois reported adjusting their injection drug practices, often by partially injecting drugs via "test shots" when they perceived that their drug sample contained fentanyl. Wanting to minimize his risk of fatal overdose after having witnessed and rescued many people from accidental overdoses, William described consistent partial injection and denied any personal instance of overdose: "[Fentanyl will] kill you if you don't know what 
you're doing. I always test products, you know. I make it up, and do a very small amount...like a test shot." (Illinois, preferred heroin). Likewise, Michael described his usual practice of injecting only small doses of drugs at a time in order to "test" the potency of the sample: "I always test my bag, you know. I try to make sure of it... let's say for instance, I'm going to shoot four or five batches. I test with one first" (NYC, preferred methamphetamine).

However, a number of participants reported not modifying injection practices if they knew or suspected their drug had fentanyl in it. Jason for instance only used test strips out of curiosity, to know for sure if his sample was adulterated with fentanyl. After testing his sample, Jason said he would continue to inject as he usually would:

I got the [fentanyl test strips] from the [SSP]. I used test strips on whatever I was doing and it actually tested positive for Fentanyl, which kind of surprised me because I didn't think that there was fentanyl in it at all... I said, 'Wow, that tested positive,' and then I do it anyway. I think the test strips are cool, you know, just as a gauge for [fentanyl]. (lllinois, preferred heroin)

Participants in both locations used a variety of techniques to gauge whether or not their drugs were adulterated with fentanyl. While this led to modification of drug use patterns for some participants, others did not. The following section describes how participants navigated reversing overdoses, when they occurred.

\section{Overdose Reversal Practices}

In contrast to other themes that emerged in our data, there were significant geographical differences between overdose reversal practices among PWID in rural Illinois and those in NYC. In particular, participants describe different initial interventions to reverse opioid overdoses in people who are unresponsive, cyanotic, and/or apneic. In rural Illinois, participants' descriptions of overdose experiences, whether during their own recent overdose or an overdose they witnessed, rarely mentioned naloxone. Instead, the most commonly described overdose response was shocking the individual with cold water. For example, Tom described that during his most recent overdose, his friend used a combination of cold water and recue breathing until he was revived:

I knew that I got a lot more, like almost all of [the drugs] we had put in there. And...she looked at me and that was the last thing I knew. And like two hours later... I wake up on the floor covered in fucking dog hair and ice cold, wet towels, just exhausted, you know, collapsed on the floor. [My friend] breathed for me for two hours. The heart never stopped, but only because she kept good oxygen. (Illinois, prefers heroin)

Participants' descriptions of how they responded to overdoses also revealed barriers to naloxone use, such as fear of the opioid withdrawal the naloxone receiver would experience, as described by Fiona in relation to her husband's overdose:

It was just God-awful. His heart never fully stopped, but his breathing was gone. But I shocked him with some ice towels.... t take Suboxone, which has naloxone in it. I mean, I think it's great for some opiates, but 
man, when you don't need it, naloxone really sucks. It's thrown me into a withdrawal before and it made me sick. (Illinois, preferred heroin)

For Samantha, cold water baths were the only overdose response she was aware of:

I [saw] my daughter's dad hit the floor, go blue. It freaked me out. Me and another friend, all we could think of was to put him in the bathtub and turn on the cold water. I've been told before that for someone that had overdosed, put him in the bathtub, cold water, ice. That's the only thing I've ever been told about an overdose. Put him in the bathtub, turn on pure cold water. Eventually I called the ambulance. (preferred methamphetamine)

Even participants who were trained on using naloxone, such as Bianca, forgot about naloxone and used ice as a first response intervention:

I have heard of naloxone, I forgot about that. I think it's a good thing to have around. I really do. The [SSP] told me how to use it and gave me some. I've never given it, but l've seen other people do it... Yes [I've witnessed an overdose]. They just fell and then started shaking and I guess, having convulsions then turning blue. We started...putting ice on their hot spots, like under their armpits or their groin area. It worked. (Illionis, preferred heroin)

Additionally, one participant asked a question related to legal repercussions that revealed how mistrust in the police may be an additional barrier to naloxone use: I think that if people were to somehow obtain Narcan... as long as they have a pocket full Narcan, and no dope on them, can the cops bust them and interrogate them because of the fact that they have Narcan on them? I don't know exactly what the answer is to that. (David, Illinois, preferred methamphetamine).

In comparison, most participants in NYC described overdose responses with rapid activation of emergency services and naloxone as first-line interventions for overdoses. Related to his own recent overdose experience, Blake described:

I [used naloxone]...on my goddamn self. I had the Narcan in my pocket...I always got a Narcan. I got some in my bag right here right now. I always carry the stuff on me... I had it in my pocket and I don't know what made me open it it... I felt [the overdose coming]. I couldn't even feel my shoulder... I felt something numb, like this side was numbing. That's what made me [administer naloxone]. I know it was an overdose. (NYC, preferred methamphetamine)

Similarly, Dana described habitually keeping multiple doses of naloxone nearby, which was needed to reverse a friend's overdose:

Three or four months ago, my friend overdosed. It was fentanyl. But I had the Narcan that I got from the [SSP] so I brought her back...She was in the bathroom and I heard her fall...I went in the bathroom and I put [naloxone] in her nose in one nostril and then the other nostril. I used the whole naloxone and she didn't come back. She was like turning purple. So then I tried using CPR and that didn't work so I hit her 
again with naloxone, the other one that we had in the house and then she came back. Two things of naloxone did bring her back... I usually carry naloxone with me regularly. (preferred methamphetamine)

Rebecca describes a similar situation in which her friend was able to successfully reverse an overdose with naloxone which he carried on his person: My roommate was walking into the corner store to get a cigarette and out of nowhere this girl comes running. She's like, 'He's overdosing, throwing up.' So he happened to have naloxone in his pocket and he shot it in the kid's nose and finally, the kid came back (NYC, preferred methamphetamine). In addition to PWID participant narratives, KIs contextual structural factors that prevent overdose mortality. For example, one practice put in place to respond to overdoses within NYC SSPs, which was not discussed in Illinois, is to time clients when they use the bathroom. It was explained that checking on a client within 7 minutes is sufficient time to administer Naloxone and prevent overdose mortality. One participant who worked at the SSP describes that the SSP started doing this after finding a client in the bathroom experiencing an overdose:

I think probably two people I've crossed [within the SSP] ODed but... they were revived. We caught it in time, because we had a client that was stuck in the bathroom for a long time and when I happened to knock and open the door he was on the floor. We had to close it down and take care of him....You've got 7 minutes in the bathroom and if you're in there longer than 7 minutes I'll go knock. If you don't answer or respond, then I open the door. (Timothy, NYC, preferred heroin)

Maria, a KI, also expresses frustration of the lack of funding for these services, which are pivotal structural interventions to reduce overdose mortality:

Everyone that comes in to use the bathroom, they sign up, they get 15 minutes. There's a designated person that just watches the two bathrooms. They knock on the door every three minutes, make sure they're okay if they're not... we've got an AED [automated external defibrillator], oxygen, um, a BVM [BVM mask] mask. We've got Narcan obviously... The basics to bring someone back if they do overdose, which thank God we've not had any fatalities... What frustrates me is that there's very little funding for running our bathrooms for overdose prevention. (NYC)

Despite higher rates of naloxone use, overdose reversal was still reported as problematic by some PWID. Luke admitted that it was difficult for him to carry naloxone because of housing instability. He said that he carries naloxone on his person only sometimes, but does keep a rescue kit in a shelter locker:

I have naloxone at the shelter, it's in my locker. I usually don't carry it with me all the time because there's no way that I would use until tonight when I'm at the shelter. It's also the time of the year. I don't carry a backpack now because when it starts getting a little colder I'll probably have my backpack and I'll have some naloxone in there. (NYC, preferred heroin)

Similar to the Illinois participants, Jessie described how fear of police negatively impacted his overdose response: 
I've been hanging out with this kid every day for the past two months... We cop the oxy 30s, we get some Xannies with it. He eats about 10 of them, he took a couple of bars. He passes out... I look at him, he's fucking completely blue. I fucking slam [my breaks]... I'm slapping him, I can't get him up... I'm driving... Know the first thing came to my mind was? Take his body and put him back in his car... Scared to death with the drugs and everything... So what I did was I fucking pull into my house, I take the drugs... out of his pocket, I throw it on my lawn. I get back in my car, I call the ambulance... They come, they put him on oxygen, and he wakes up on the spot. (Jesse, NYC, preferred heroin)

Kelly, a KI and nurse at an SSP in New York City, recognized systemic and institutional problems related to opioid overdose. She explained that there are frequent delays in emergency response times for overdoserelated calls and expressed frustration with the lack of funding for overdose education and reversal programs:

Our staff are pretty well trained. They have gotten to a point where they can stay calm, react, and keep the drop-in center calm. It takes EMS a really long time to get here... We have a policy here with that anyone that calls 911, you cannot mention overdose or drug use, you just say unconscious not breathing because this area is so saturated with overdose and drug-related 911 calls that EMS kind of skips them sometimes, which is like terrible but I also realize it's systemic. Like they're overworked and they're struggling... with what's going on.

\section{Discussion}

By comparing narratives from rural and urban PWID, we were able to describe how perceptions of local drug markets and strategies to prevent and reverse overdose differed by geographic area. Common across both locations was awareness that fentanyl has been mixed with drugs within the local drug market. In the context of NYC, this finding was not surprising, given that illicitly manufactured fentanyl has historically been predominantly concentrated within the east coast heroin market (2). However, rural participants in our study perceived that illicitly manufactured fentanyl has been widely mixed into their methamphetamine drug supply, which, until recently has been perceived as rarely occurring (43). This finding contributes to the growing body of new research demonstrating recent US trends of increased fentanyl in stimulants, such as methamphetamines and cocaine (44), suggesting the need for overdose interventions tailored to address dependence on both opioids and stimulants.

One of the most prominent contrasts emerging from our data was geographic differences in naloxone use. None of the PWID in rural Illinois described the use of naloxone during recently witnessed overdoses. In contrast, participants in NYC described frequently using naloxone in the event of overdose. A major driver of differential naloxone use may be decreased access to naloxone in rural compared to urban locations. For example, beginning in 2017 NYC invested $\$ 38$ million per year to combat opioid overdose deaths through the HealingNYC initiative (45). Part of this initiative has been to distribute naloxone. NYC also has pharmacist-distributed naloxone that does not require a prescription. Therefore, someone can get naloxone free at a participating pharmacy, and if the pharmacy does not offer free naloxone, a 
number of pharmacies offer a co-pay assistance program (46). Broadly speaking, states with similar naloxone access laws granting direct authority to pharmacists to provide naloxone tend to experience declines in fatal opioid-related overdoses (47). In contrast, while pharmacists in Illinois can dispense naloxone without a prescription (48), the rural landscape of participating pharmacies may make it more difficult to access due to large distances to participating pharmacies (49) Fear of stigma or disclosure of drug use from the provider may also deter PWID from attempting to acquire naloxone. Additionally, practices such as the bathroom policies within SSPs to reduce overdose that explicitly incorporated naloxone, as described by our Key Informants, have led to greater integration of naloxone in PWID's daily surroundings. This pervasiveness of naloxone may provide PWID in NYC with a less stigmatizing environment towards injection drug use, which may in turn mitigate fears of carrying naloxone (50-52). Additionally, participants in rural Illinois, but not NYC, discussed hesitancy to administer naloxone due to concerns related to post-reversal side effects, such as severe opioid withdrawal. This difference likely reflects the local environments of both locations, including the normalization of naloxone, in part due to structural differences in NYC described above. Therefore, developing infrastructures to support naloxone distribution and use, as well as funding initiatives, may be particularly beneficial for the rural Illinois community. In addition, education about the effects of naloxone after administration, with a focus on communication skills to mitigate potential post-reversal conflict between the naloxone administrator and the naloxone recipient would help (53).

Although narratives from NYC participants described more comfort with using naloxone, a key barrier to naloxone use and calling emergency respondents that emerged in both locations was the fear of police response. Both New York and Illinois have enacted Good Samaritan Laws (GSL) that offer legal protection to people who call 911 or seek medical attention related to an opiate overdose (54). While these laws have been associated with reductions in opioid related mortality (55), our data as well as others $(56,57)$, suggests that participants are either unaware of GSL or that distrust and fear of police remain a barrier to overdose response despite GSL. These findings suggest interventions are needed to further support PWID in both locations to use Naloxone and call 911 when witnessing an overdose. Given the widespread fear of legal repercussions associated with overdose responses, guidance and education are needed to inform PWID, police, and the public about policies that legalize the possession of naloxone and limit arrest and prosecution for carrying naloxone with other injection paraphernalia $(58,59)$.

However, in many states the protections afforded by these laws are limited, constraining their effectiveness at reducing overdose-related harms. States and localities should expand criminal-legal protections for low-level drug related violations when witnesses call 911 for an overdose.

A first line of defense for avoiding overdoses in both locations was purchasing drugs from trusted and consistent drug sellers who they believed would alert them if fentanyl was in the supply, which has been widely reported among samples of urban PWID $(15-18,60)$, but to our knowledge has not been reported as occurring in rural locations. This finding, along with our finding related to how SSPs in urban NYC relay information about "bad batches" that may contain fentanyl, highlight the important role that social networks of PWID in both urban and rural locations play in fentanyl-related information diffusion. Social networks of PWID have long been recognized as a source of information sharing, advice seeking, and 
support (61-65), and can contribute to uptake of pro-health behaviors and health and social services (62). For example, Sherman et al. (2020) report that among participants in an overdose prevention and naloxone distribution program in Baltimore, MD, many were highly motivated to share information on overdose prevention and management, particularly the use of naloxone, to their peers and family (66). Social networks could therefore be leveraged to increase awareness and use of use of other overdose prevention strategies, such as fentanyl test strips due to their low use in both geographic locations, and of naloxone particularly in rural Illinois. It is important to note that social distancing as a result of COVID19 may challenge PWID's ability to access such information from trusted sources within their network (67). This will likely be a prominent issue for PWID in both rural and urban locations, though potentially amplified for rural PWID who already have less access to illicit street drug sellers due lower population density and increased transportation issues compared to urban locations $(68,69)$. In the event that COVID-19 has disrupted PWID's ability to locate trusted drug sellers, SSPs may play an even greater role in connecting PWID to information about drugs containing fentanyl.

Like all studies, there are important limitations. First, we had to terminate data collection due to COVID-19, though we believe we were able to reach saturation (i.e., the point at which no new data emerges in interviews) (70). Also, this study sampled PWID who were actively using SSP services. There are many PWID who do not use harm reduction services who are not represented in this study, and who may be more at risk for fatal overdoses if they do not have access to harm reduction services such as fentanyl testing strips, naloxone, and the latest harm reduction information. Further, the SSP services that we partnered with may differ from other SSPs in the US and therefore our data may not be generalizable to PWID engaged in harm reduction. Despite these limitations, this study makes key contributions to science. This study provides a nuanced understanding of rural-urban differences in overdose risk and prevention strategies. Key differences emerged related to structural issues by location, which affected drug supply and access to naloxone. By uniquely focusing on rural and urban differences, we were able to tease out important structural issues that can exacerbate or mitigate overdoses. These findings should inform regional-specific interventions to reduce overdose risk among PWID. Although naloxone cannot reverse a stimulant overdose, it should still be provided to people who use stimulants in locations where fentanyl is in the stimulant supply.

\section{Abbreviations}

Persons who inject drugs (PWID); New York City (NYC); syringe service provider (SSP); Ending Transmission of HIV, HCV, and Overdose in Rural Communities of People Who Inject Drugs (ETHIC); key informant (KI); emergency medical services (EMS); Good Samaritan Laws (GSL)

\section{Declarations}

Author Contributions: SW and DO were PIs on the grants. SW and DF conducted interviews. SW and BM coded interviews. SW and MF conceptualized the study, analyzed data, and wrote the manuscript. DF, TT, $\mathrm{BM}, \mathrm{SF}$, and DO provided substantive feedback and editing. All authors approved the final manuscript. 
Availability of data and materials: Data can be made available from the corresponding author on reasonable request.

Ethics approval and consent to participate: This study received research ethics approval from New York University Institutional Review Board (NYU IRB). A reliance agreement was constructed between NYU IRB and Southern Illinois University (SIU) for data collection in rural southern Illinois.

Acknowledgements: The authors would like to thank Johnny Bresset, Rebecca Bolinski, Wiley Jenkins, Mai Pho, and Brent Van Ham for their support and contributions to study enrollment and data collection. We thank Alexis Roth for her feedback on the development of the qualitative guide. We also thank all the participants of this study and our community partners [unnamed to protect their identity]. Without them, this research could not have been conducted.

Funding source: This work was funded by the NIH Clinical and Translational Science Awards Program (UL1TR001445) and National Institute on Drug Abuse (NIDA) [grant numbers P30DA01104, PI: Hagan, T32 DA007233-31, PI: Falkin; and R25DA026401; PI Avelardo Valdez, 4UH3DA044829-03 PIs: Jenkins, Pho)

Competing Interests: The authors have no conflicts of interest.

\section{References}

1. Degenhardt L, Whiteford HA, Ferrari AJ, Baxter AJ, Charlson FJ, Hall WD, et al. Global burden of disease attributable to illicit drug use and dependence: findings from the Global Burden of Disease Study 2010. The Lancet. 2013;382(9904):1564-74.

2. Prevention CfDCa. Increase in Fatal Drug Overdoses Across the United States Driven by Synthetic Opioids Before and During the COVID-19 Pandemic. 2020.

3. Consistent With Nationwide Trends, Overdose Deaths Rise in New York City in First Quarter of 2020 [press release]. 2020.

4. Stephenson J, editor Drug Overdose Deaths Head Toward Record Number in 2020, CDC Warns. JAMA Health Forum; 2020: American Medical Association.

5. Jones CM, Einstein EB, Compton WM. Changes in Synthetic Opioid Involvement in Drug Overdose Deaths in the United States, 2010-2016. JAMA. 2018;319(17):1819.

6. O'Donnell JK, Halpin J, Mattson CL, Goldberger BA, Gladden RM. Deaths involving fentanyl, fentanyl analogs, and U-47700-10 states, July-December 2016. MMWR Morbidity and mortality weekly report. 2017;66(43):1197.

7. Administration DE. Counterfeit prescription pills containing fentanyls: a global threat. Springfield, VA: US Drug Enforcement Administration. 2016.

8. Rouhani S, Park JN, Morales KB, Green TC, Sherman SG. Harm reduction measures employed by people using opioids with suspected fentanyl exposure in Boston, Baltimore, and Providence. Harm 
Reduction Journal. 2019;16(1).

9. Ciccarone D. Fentanyl in the US heroin supply: a rapidly changing risk environment. The International journal on drug policy. 2017;46:107.

10. Stewart B. Demand for fentanyl test strips booms- But test is not widely available. CBC News. Toronto, Canada: CBC/Radio-Canada; 2017.

11. Wheeler E, Jones TS, Gilbert MK, Davidson PJ. Opioid overdose prevention programs providing naloxone to laypersons-United States, 2014. MMWR Morbidity and mortality weekly report. 2015;64(23):631.

12. Beswick T, Best D, Bearn J, Rees S, Gossop M, Coomber R, et al. From salt injection to naloxone: accuracy and myths in peer resuscitation methods for opiate overdose. Journal of Drug Issues. 2002;32(4):1103-14.

13. Sherman SG, Gann DS, Scott G, Carlberg S, Bigg D, Heimer R. A qualitative study of overdose responses among Chicago IDUs. Harm Reduction Journal. 2008;5(1):1-5.

14. Mars SG, Ondocsin J, Ciccarone D. Toots, tastes and tester shots: user accounts of drug sampling methods for gauging heroin potency. Harm reduction journal. 2018;15(1):1-10.

15. Carroll JJ, Rich JD, Green TC. The protective effect of trusted dealers against opioid overdose in the US. International Journal of Drug Policy. 2020;78:102695.

16. McKnight C, Des Jarlais D. Being “hooked up” during a sharp increase in the availability of illicitly manufactured fentanyl: adaptations of drug using practices among people who use drugs (PWUD) in New York City. International Journal of Drug Policy. 2018;60:82-8.

17. Bardwell G, Boyd J, Arredondo J, McNeil R, Kerr T. Trusting the source: the potential role of drug dealers in reducing drug-related harms via drug checking. Drug and alcohol dependence. 2019;198:16.

18. Mateu-Gelabert P, Sandoval M, Meylakhs P, Wendel T, Friedman SR. Strategies to avoid opiate withdrawal: implications for HCV and HIV risks. International Journal of Drug Policy. 2010;21(3):17985.

19. Moss RB, Carlo DJ. Higher doses of naloxone are needed in the synthetic opioid era. Substance abuse treatment, prevention, and policy. 2019;14(1):1-6.

20. Faul M, Lurie P, Kinsman JM, Dailey MW, Crabaugh C, Sasser SM. Multiple naloxone administrations among emergency medical service providers is increasing. Prehospital Emergency Care. 2017;21(4):411-9.

21. Paulozzi LJ, Xi Y. Recent changes in drug poisoning mortality in the United States by urban-rural status and by drug type. Pharmacoepidemiology and drug safety. 2008;17(10):997-1005.

22. Havens JR, Oser CB, Leukefeld CG, Webster JM, Martin SS, O'Connell DJ, et al. Differences in prevalence of prescription opiate misuse among rural and urban probationers. The American journal of drug and alcohol abuse. 2007;33(2):309-17. 
23. Dunn KE, Barrett FS, Yepez-Laubach C, Meyer AC, Hruska BJ, Petrush K, et al. Opioid overdose experience, risk behaviors, and knowledge in drug users from a rural versus an urban setting. Journal of substance abuse treatment. 2016;71:1-7.

24. Rigg KK, Monnat SM, Chavez MN. Opioid-related mortality in rural America: geographic heterogeneity and intervention strategies. International Journal of Drug Policy. 2018;57:119-29.

25. Mazhnaya A, O'Rourke A, White RH, Park JN, Kilkenny ME, Sherman SG, et al. Fentanyl Preference among People Who Inject Drugs in West Virginia. Substance Use \& Misuse. 2020:1-7.

26. Daniulaityte R, Juhascik MP, Strayer KE, Sizemore IE, Zatreh M, Nahhas RW, et al. Trends in fentanyl and fentanyl analogue-related overdose deaths-Montgomery County, Ohio, 2015-2017. Drug and alcohol dependence. 2019;198:116-20.

27. Ostrach B, Buer LM, Armbruster S, Brown H, Yochym G, Zaller N. COVID-19 and Rural Harm Reduction Challenges in the US Southern Mountains. The Journal of Rural Health. 2020.

28. Cao Y, Stewart K, Wish E, Artigiani E, Sorg MH. Determining spatial access to opioid use disorder treatment and emergency medical services in New Hampshire. Journal of substance abuse treatment. 2019;101:55-66.

29. Borders TF, Booth BM, Stewart KE, Cheney AM, Curran GM. Rural/urban residence, access, and perceived need for treatment among African American cocaine users. The Journal of Rural Health. 2015;31(1):98-107.

30. McLuckie C, Pho MT, Ellis K, Navon L, Walblay K, Jenkins WD, et al. Identifying areas with disproportionate local health department services relative to opioid overdose, HIV and hepatitis $\mathrm{C}$ diagnosis rates: a study of rural Illinois. International journal of environmental research and public health. 2019;16(6):989.

31. Heil SH, Sigmon SC, Jones HE, Wagner M. Comparison of characteristics of opioid-using pregnant women in rural and urban settings. The American journal of drug and alcohol abuse. 2008;34(4):46371.

32. Hirchak KA, Murphy SM. Assessing differences in the availability of opioid addiction therapy options: rural versus urban and American Indian reservation versus nonreservation. The Journal of Rural Health. 2017;33(1):102-9.

33. Stein BD, Pacula RL, Gordon AJ, Burns RM, Leslie DL, Sorbero MJ, et al. Where is buprenorphine dispensed to treat opioid use disorders? The role of private offices, opioid treatment programs, and substance abuse treatment facilities in urban and rural counties. The Milbank Quarterly. 2015;93(3):561-83.

34. Jarlais DCD, Nugent A, Solberg A, Feelemyer J, Mermin J, Holtzman D. Syringe service programs for persons who inject drugs in urban, suburban, and rural areas-United States, 2013. Morbidity and mortality weekly report. 2015;64(48):1337-41.

35. Rost K, Fortney J, Zhang M, Smith J, Smith Ir GRS. Treatment of depression in rural Arkansas: policy implications for improving care. The Journal of Rural Health. 1999;15(3):308-15.

36. Marshall MN. The key informant technique. Family practice. 1996;13(1):92-7. 
37. Charmaz K. Constructing grounded theory: A practical guide through qualitative analysis: sage; 2006.

38. Polit DF, Beck CT. Nursing research: Generating and assessing evidence for nursing practice: Lippincott Williams \& Wilkins; 2008.

39. Miles MB, Huberman AM, Saldaña J. Qualitative data analysis: A methods sourcebook. 3rd. Thousand Oaks, CA: Sage; 2014.

40. Geertz C. Thick Description: toward and Interpretative Theory of Culture. Readings in the Philosophy of Social Science. M. Martin and LC McIntyre. Cambridge, MA; 1994.

41. Orne J, Bell M. An invitation to qualitative fieldwork: A multilogical approach: Routledge; 2015.

42. Kaiser K. Protecting respondent confidentiality in qualitative research. Qualitative health research. 2009;19(11):1632-41.

43. Administration DE. National Drug Threat Assessment. 2019.

44. Twillman RK, Dawson E, LaRue L, Guevara MG, Whitley P, Huskey A. Evaluation of Trends of NearReal-Time Urine Drug Test Results for Methamphetamine, Cocaine, Heroin, and Fentanyl. JAMA Network Open. 2020;3(1):e1918514-e.

45. NYC Office of the Mayor "De Blasio Administration Launches New Initiative To Combat Opioid Epidemic" March 2017 [press release]. NYC Health and Hospitals2020.

46. Health; NYCDo. Naloxone 2020 [Available from: https://www1.nyc.gov/site/doh/health/healthtopics/naloxone.page.

47. Abouk R, Pacula RL, Powell D. Association between state laws facilitating pharmacy distribution of naloxone and risk of fatal overdose. JAMA internal medicine. 2019;179(6):805-11.

48. Health; IDo. Naloxone 2020 [Available from: https://www.dph.illinois.gov/naloxone.

49. Health IDoP. Opioid Data Dashboard 2020 [Available from: https://idph.illinois.gov/OpioidDataDashboard/.

50. Bolinski R, Ellis K, Zahnd WE, Walters S, McLuckie C, Schneider J, et al. Social norms associated with nonmedical opioid use in rural communities: a systematic review. Translational behavioral medicine. 2019;9(6):1224-32.

51. Muncan B, Walters SM, Ezell J, Ompad DC. "They look at us like junkies": influences of drug use stigma on the healthcare engagement of people who inject drugs in New York City. Harm reduction journal. 2020;17(1):1-9.

52. Ezell JM, Walters S, Friedman SR, Bolinski R, Jenkins WD, Schneider J, et al. Stigmatize the use, not the user? Attitudes on opioid use, drug injection, treatment, and overdose prevention in rural communities. Social Science \& Medicine. 2020:113470.

53. Dayton L, Gicquelais RE, Tobin K, Davey-Rothwell M, Falade-Nwulia O, Kong X, et al. More than just availability: Who has access and who administers take-home naloxone in Baltimore, MD. PloS one. 2019;14(11):e0224686.

54. Legislatures NCoS, editor Drug Overdose Immunity and Good Samaritan Laws2014: National Conference of State Legislatures. 
55. Rees DI, Sabia JJ, Argys LM, Dave D, Latshaw J. With a little help from my friends: The effects of good Samaritan and naloxone access laws on opioid-related deaths. The Journal of Law and Economics. 2019;62(1):1-27.

56. Latimore AD, Bergstein RS. "Caught with a body" yet protected by law? Calling 911 for opioid overdose in the context of the Good Samaritan Law. International Journal of Drug Policy. 2017;50:829.

57. Ellis K, Walters S, Friedman S, Ouellet L, Ezell J, Rosentel K, et al. Breaching trust: A qualitative study of healthcare experiences of people who use drugs in a rural setting. Front Sociol 5: 593925 doi: 103389/fsoc. 2020.

58. Davis $C$, Webb D, Burris $S$. Changing law from barrier to facilitator of opioid overdose prevention. The Journal of Law, Medicine \& Ethics. 2013;41(1_suppl):33-6.

59. Lieberman A, Davis C. Legal Interventions to Reduce Overdose Mortality: Naloxone Access Laws. The Network for Public Health Law; 2021.

60. Betsos A, Valleriani J, Boyd J, Bardwell G, Kerr T, McNeil R. "I couldn't live with killing one of my friends or anybody": A rapid ethnographic study of drug sellers' use of drug checking. International Journal of Drug Policy.87:102845.

61. Goldsmith DJ. Communicating social support: Cambridge University Press; 2004.

62. Rogers Everett M. Diffusion of innovations. New York. 1995;12.

63. Felsher M, Koku E, Lankenau S, Brady K, Bellamy S, Roth AM. Motivations for PrEP-Related Interpersonal Communication Among Women Who Inject Drugs: A Qualitative Egocentric Network Study. Qualitative Health Research. 2020:1049732320952740.

64. Walters SM, Coston B, Neaigus A, Rivera AV, Starbuck L, Ramirez V, et al. The role of syringe exchange programs and sexual identity in awareness of pre-exposure prophylaxis (PrEP) for male persons who inject drugs. International Journal of Drug Policy. 2020;77:102671.

65. Walters SM, Reilly KH, Neaigus A, Braunstein S. Awareness of pre-exposure prophylaxis (PrEP) among women who inject drugs in NYC: the importance of networks and syringe exchange programs for HIV prevention. Harm Reduction Journal. 2017;14(1):40.

66. Sherman SG, Gann DS, Tobin KE, Latkin CA, Welsh C, Bielenson P. "The life they save may be mine": diffusion of overdose prevention information from a city sponsored programme. International Journal of Drug Policy. 2009;20(2):137-42.

67. Glick SN, Prohaska SM, LaKosky PA, Juarez AM, Corcorran MA, Des Jarlais DC. The impact of COVID-19 on syringe services programs in the United States. AIDS and Behavior. 2020;24(9):2466-8.

68. Walters SM, Seal DW, Stopka TJ, Murphy ME, Jenkins WD. COVID-19 and People Who Use Drugs-A Commentary. Health behavior and policy review. 2020;7(5):489-97.

69. James KE, Wagner FA, Anthony JC. Regional varation in drug purchase opportunity among youths in the United States, 1996-1997. Journal of Urban Health. 2002;79(1):104-12. 
70. Mason M, editor Sample size and saturation in PhD studies using qualitative interviews. Forum qualitative Sozialforschung/Forum: qualitative social research; 2010.

\section{Tables}


Table 1. PWID Demographics $(n=59)$

\begin{tabular}{|c|c|c|c|}
\hline & Total & NYC $(n=40)$ & Illinois $(n=19)$ \\
\hline & $\mathrm{N}(\%)$ & $\mathrm{N}(\%)$ & $\mathrm{N}(\%)$ \\
\hline \multicolumn{4}{|l|}{ Gender } \\
\hline Male & $33(55.9)$ & $24(60.0)$ & $9(47.4)$ \\
\hline Female & $24(40.7)$ & $14(35.0)$ & $10(52.6)$ \\
\hline Transwoman & $2(3.4)$ & $2(5.0)$ & $0(0.0)$ \\
\hline Age (mean, std) & $40.2(9.3)$ & $41.9(9.5)$ & $36.7(8.1)$ \\
\hline \multicolumn{4}{|l|}{ Race/Ethnicity } \\
\hline White & $25(42.4)$ & $8(20.0)$ & $17(89.4)$ \\
\hline Hispanic or Latinx & $18(30.5)$ & $18(45.0)$ & $0(0.0)$ \\
\hline Black or African American & $6(10.2)$ & $5(12.5)$ & $1(5.3)$ \\
\hline Multiracial & $6(10.2)$ & $6(15.0)$ & $0(0.0)$ \\
\hline Not Specified & $3(5.1)$ & $3(7.5)$ & $0(0.0)$ \\
\hline Native American & $1(1.7)$ & $0(0.0)$ & $1(5.3)$ \\
\hline \multicolumn{4}{|l|}{ Sexual Orientation } \\
\hline Heterosexual or Straight & $51(86.4)$ & $34(85.0)$ & $17(89.4)$ \\
\hline Bisexual & $3(5.1)$ & $1(2.5)$ & $2(10.6)$ \\
\hline Gay or Lesbian & $1(1.7)$ & $1(2.5)$ & $0(0.0)$ \\
\hline Not Specified & $4(6.8)$ & $4(10.0)$ & $0(0.0)$ \\
\hline \multicolumn{4}{|l|}{ Education } \\
\hline Less than High School & $12(20.3)$ & $9(22.5)$ & 3 \\
\hline High School or GED & $20(33.9)$ & $13(32.5)$ & 7 \\
\hline Some College & $20(33.9)$ & $12(30.0)$ & 8 \\
\hline Bachelor's Degree & $2(3.4)$ & $1(2.5)$ & 1 \\
\hline Graduate Degree & $1(1.7)$ & $1(2.5)$ & 0 \\
\hline Not Specified & $4(6.8)$ & $4(10.0)$ & 0 \\
\hline Currently Injects Drugs & $51(86.4)$ & $32(80.0)$ & $19(100.0)$ \\
\hline Drug Preference & & & \\
\hline
\end{tabular}




\begin{tabular}{|llll|} 
Preferred opioids & $31(52.5)$ & $24(60.0)$ & $7(36.8)$ \\
\hline Preferring stimulants & $28(47.5)$ & $16(40.0)$ & $12(63.2)$ \\
\hline
\end{tabular}




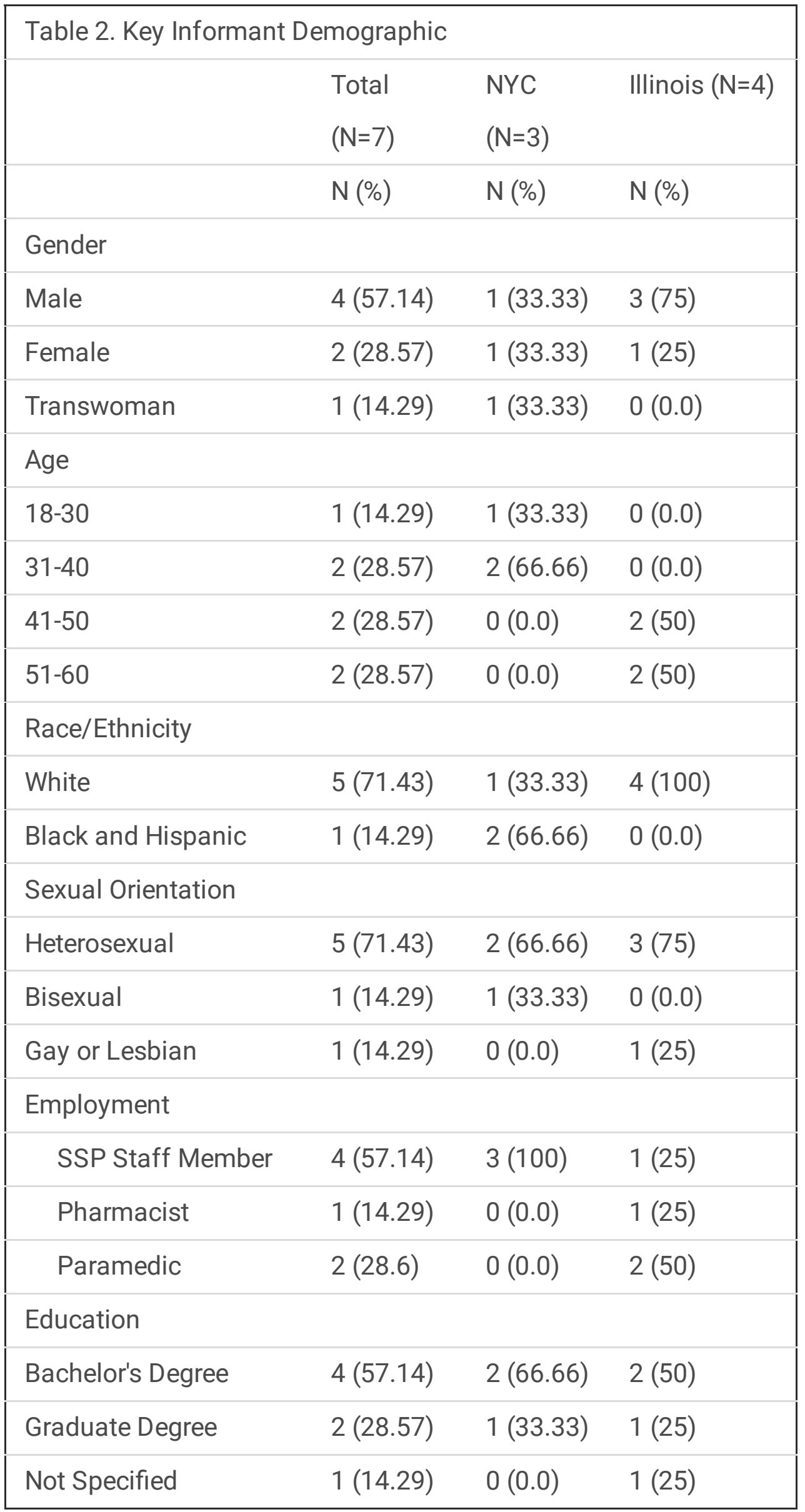

